\title{
An interlacing networking model for TD-LTE power private wireless network in multiple frequency bands
}

\author{
WANG Hao ${ }^{\text {1a }}$, CHEN Yongtao ${ }^{1}$, ZHONG Yuqing ${ }^{1}$ \\ ${ }^{1}$ Guangzhou Power Supply Co.Ltd. , Guangzhou, Guangdong, 510000, China
}

\begin{abstract}
TD-LTE power private wireless network develops rapidly in recent years for the communication of distribution and sale of electricity in smart grid. The mainstream technologies of TD-LTE power private wireless network are $1.8 \mathrm{GHz}$ TD-LTE power private wireless network and $230 \mathrm{MHz}$ TD-LTE power private wireless network. These two kinds of wireless technologies are now separately constructing network in different power supply area, which will cause Co-Channel interference in the adjacent cells and signal blind zones. This paper present an interlacing networking model for TD-LTE power private wireless network in multiple frequency bands, this model can reduce the Co-Channel interference in the overlap area of the base stations and promote continuous coverage performance of TD-LTE power private wireless network.
\end{abstract}

\section{Introduction}

According to the frequency assignment policy in China, power grid enterprises can use $230 \mathrm{MHz}$ and $1.8 \mathrm{GHz}$ frequency bands to construct power private wireless network, and TD-LTE technology is the most mainstream wireless communication technology. The $230 \mathrm{MHz}$ TD-LTE power private wireless network works in 40 discrete frequency points in $223 \sim 235 \mathrm{MHz}$ frequency bands, each frequency point occupies $25 \mathrm{kHz}$ bandwidth. The $1.8 \mathrm{GHz}$ TD-LTE power private wireless network works in $1790 \sim 1795 \mathrm{MHz}$ continuous frequency ${ }^{[1]}$. These two kinds of power private wireless network are now planed and constructed separately which is showed in Figure 1. In this construction model, a power supply bureau construct the $1.8 \mathrm{GHz}$ TD-LTE power private wireless network and $230 \mathrm{MHz}$ TD-LTE power private wireless network in different power supply area and the base stations in different working frequencies have no signal overlap areas. The $1.8 \mathrm{GHz}$ TD-LTE power private wireless network is constructed in urban area for the larger throughput capacity and the $230 \mathrm{MHz}$ TD-LTE power private wireless network is constructed in suburb for the better coverage performance in low frequency. The base station location of power private wireless network is restricted in the real estate of power grid enterprises like substations or office buildings ${ }^{[2]}$, which will cause the cell distance of the TDLTE power private wireless network too big or too small. Unreasonable distribution of the TD-LTE power private wireless network will cause Co-Channel interference in the adjacent cells and signal blind zones. So the research of a new networking model to reach maximum utilization of frequency resources of TD-LTE power private wireless network is very necessary.

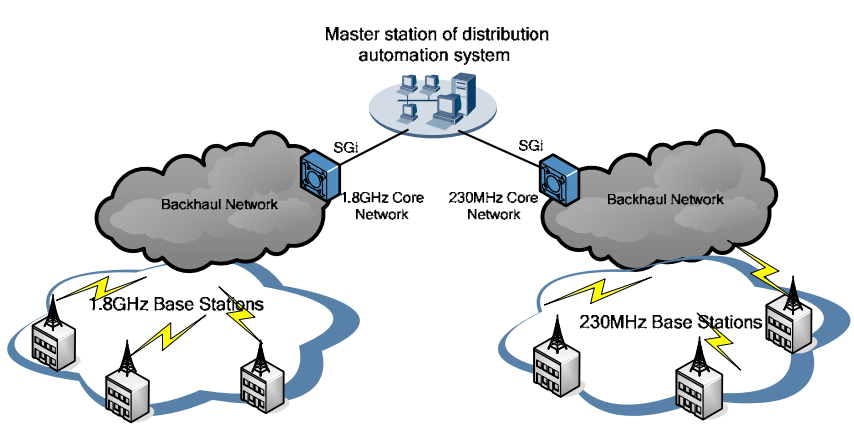

Figure 1. Current networking mode of TD-LTE power private wireless network in two frequencies.

\section{Analysis of Co-Channel interference of neighbour cells in TD-LTE power private wireless network}

When base stations of the TD-LTE power private wireless network in same frequency make an intensive construction in a power supply area, Co-Channel interference of neighbour cells is inevitable.

TD-LTE system support same frequency network, each cell occupy the whole frequency range. The frequency reuse factor of the same frequency network is 1 , which reaches the max spectrum efficiency but will cause bad cell-edge user performance because of Co-Channel interference and has high requirements of network planning optimization. TD-LTE power private wireless network is hard to meet the network planning requirements in same frequency network because the base station location is limited.

Three different frequencies division networking can solve the problem of Co-Channel interference but

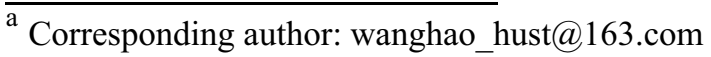


throughput will greatly decrease to one third of the max throughput.

FFR(Fractional Frequency Reuse), SFR(Soft Frequency Reuse) and other ICIC(Inter Cell Interference Coordination) technologies can reduce the Co-Channel interference of cell-edge users as well as ensure the throughput of cell-centre users, but frequency division in these kind of technologies will also cause throughput decrease of cell-edge users.

Figure 2. shows the using of SFR of $230 \mathrm{MHz}$ TDLTE power private wireless network with omnidirectional antenna.

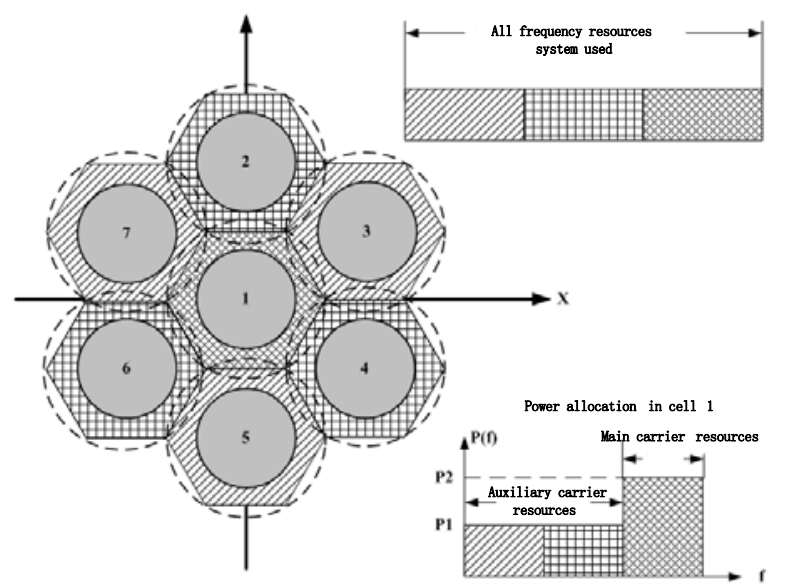

Figure 2. SFR of $230 \mathrm{MHz}$ TD-LTE power private wireless network with omnidirectional antenna.

Figure 3. shows 4 Neighbouring $230 \mathrm{MHz}$ TD-LTE power private wireless base stations in Huadu District, Guangzhou. The 230MHz TD-LTE power private wireless base stations support SFR. Table 1. shows the terminals statistics with max detach numbers in 40 days with the SFR enabled. The statistics shows that CoChannel interference of cell-edge users can cause frequently detaches of some terminals which will influence the stability of the communication, and the SFR can not completely solve this problem.

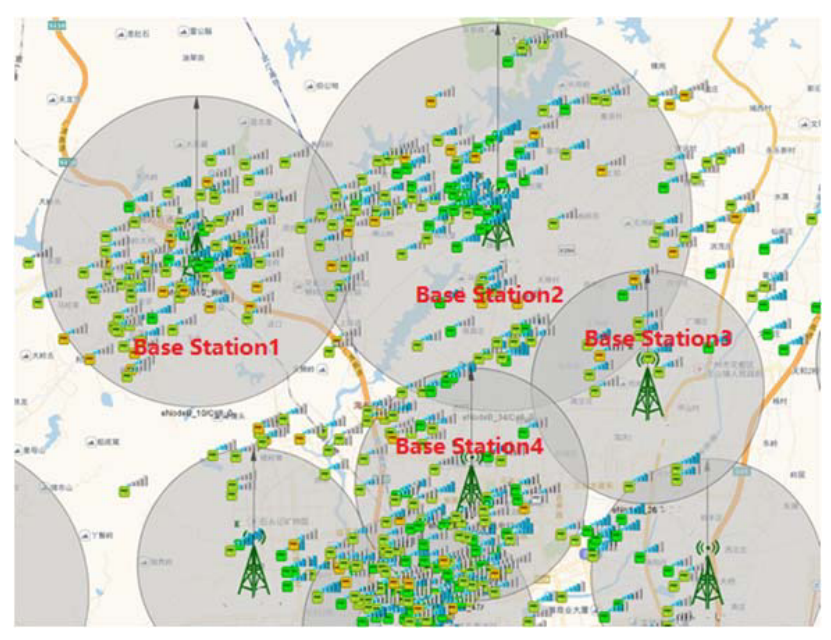

Figure 3. 4 Neighbouring 230MHz TD-LTE power private wireless base stations in Huadu District, Guangzhou.
Table 1. Terminals statistics with max detach numbers in 40 days.

\begin{tabular}{|c|c|c|}
\hline $\begin{array}{c}\text { Terminal } \\
\text { serial } \\
\text { number }\end{array}$ & Base Station & Detach numbers \\
\hline 1 & Base Station2 & 854 \\
\hline 2 & Base Station4 & 815 \\
\hline 3 & Base Station2 & 780 \\
\hline 4 & Base Station4 & 685 \\
\hline 5 & Base Station2 & 661 \\
\hline 6 & Base Station4 & 648 \\
\hline 7 & Base Station4 & 601 \\
\hline 8 & Base Station2 & 503 \\
\hline 9 & Base Station3 & 450 \\
\hline 10 & Base Station4 & 415 \\
\hline 11 & Base Station4 & 404 \\
\hline 12 & Base Station2 & 366 \\
\hline
\end{tabular}

\section{Analysis of signal blind zones in TD- LTE power private wireless network}

Figure 4. shows the emulation of the coverage capability of $1.8 \mathrm{GHz}$ TD-LTE power private wireless network in Yuexiu District, Guangzhou. 1.8GHz TDLTE power private wireless network have a lager throughput than $230 \mathrm{MHz}$ TD-LTE power private wireless network so it is always constructed in urban area like Yuexiu District which has dense distribution room distributed. The urban area have tall buildings to shield the signal transmission and $1.8 \mathrm{GHz}$ frequency has less signal coverage than $230 \mathrm{MHz}$ frequency, so the signal blind zones in $1.8 \mathrm{GHz}$ TD-LTE power private wireless network appear in the blue area in Figure 4.

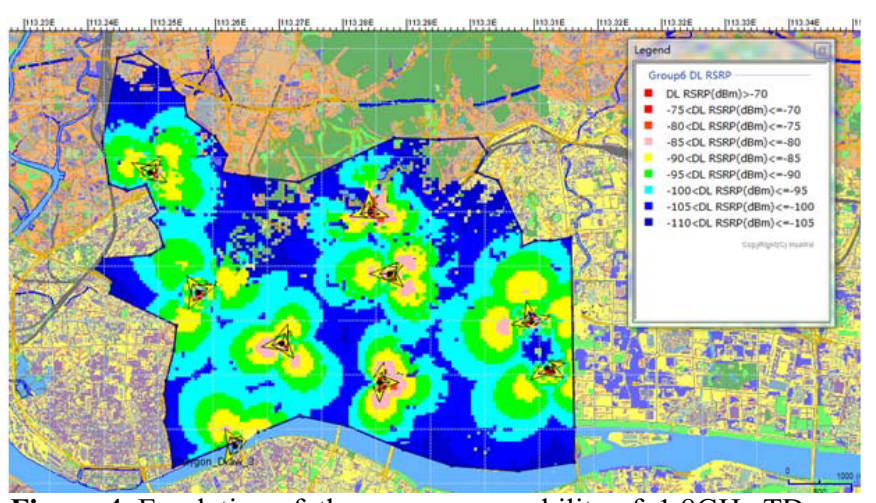

Figure 4. Emulation of the coverage capability of $1.8 \mathrm{GHz}$ TD-

LTE power private wireless network in Yuexiu District, Guangzhou.

Figure 5. shows the emulation of the coverage capability of $230 \mathrm{MHz}$ TD-LTE power private wireless network in Huadu District, Guangzhou. 230MHz TD-LTE power private wireless network uses omnidirectional antenna. It is hard to adjust the downward inclination angle to reduce the signal overlap area of the neighbouring base stations to avoid Co-Channel interference. Increase the distance between the base stations to avoid Co-Channel interference will also cause signal blind zone in the yellow area in Figure 5. 


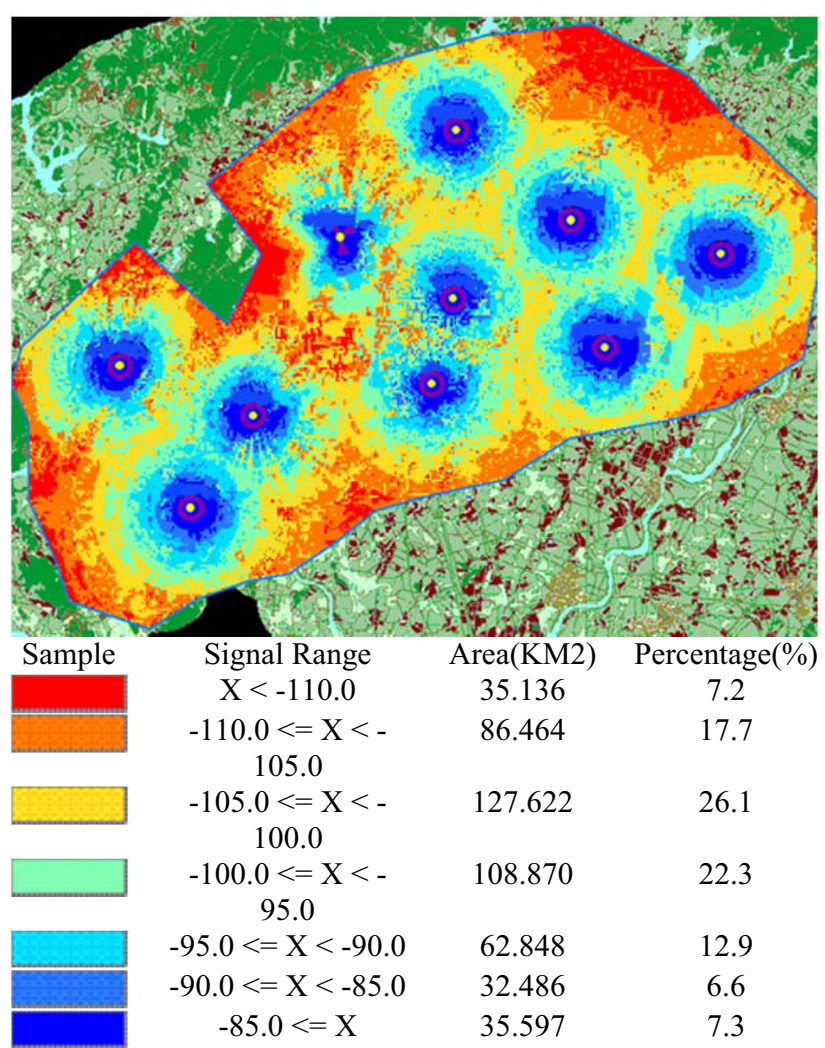

Figure 5. Emulation of the coverage capability of $230 \mathrm{MHz}$ TD-LTE power private wireless network in Huadu District, Guangzhou.

\section{An interlacing networking model for TD-LTE power private wireless network in multiple frequency bands}

According to the analysis above, using a flexible networking model of interlacing the $230 \mathrm{MHz}$ base stations and $1.8 \mathrm{GHz}$ base stations can reduce the overlap area of the base stations in same frequency to reduce CoChannel interference in neighbouring cell. Base stations in different frequencies can be very near without CoChannel interference to reduce the signal blind zone, and the base stations can use all the carrier resources in their working frequencies to reach the maximum throughput capacity. This interlacing networking model will influence the handover performance of single frequency terminal, as the position of power distribution automation and electric measurement automation equipment is fixed, this influence can be ignored.

When the base stations in two frequencies have an interlacing rate of $1: 1$, the network will be too complex to operation and maintenance. Using base stations in a frequency as the main signal coverage and base stations in other frequency as auxiliary signal coverage will reach the balance of throughput capacity and maintainability.

The $1.8 \mathrm{GHz}$ base stations working at $5 \mathrm{MHz}$ bandwidth have higher throughput capacity but lower coverage performance than $230 \mathrm{MHz}$ base stations. The $230 \mathrm{MHz}$ base stations working at $1 \mathrm{MHz}$ discrete bandwidth have lower throughput capacity but higher coverage performance than $1.8 \mathrm{GHz}$ base stations. The interlacing mode should be based on the technical characteristics of the base stations in two frequencies. This paper presents two modes of the interlacing networking model. Mode1: $1.8 \mathrm{GHz}$ base stations as the main signal coverage and $230 \mathrm{MHz}$ base stations as auxiliary signal coverage in urban area. Mode2: $230 \mathrm{MHz}$ base stations as the main signal coverage and $1.8 \mathrm{GHz}$ base stations as auxiliary signal coverage in suburb area.

Mode1 is showed in Figure 6.The $230 \mathrm{MHz}$ base stations use omnidirectional antenna with one cell(circular regions represent) and the $1.8 \mathrm{GHz}$ base stations use directional antennas with 3 cells(hexagon regions represent). Distribution rooms have a dense deployment in the urban area, so the substations with high roofing and low shelter can construct the $1.8 \mathrm{GHz}$ base stations to ensure the throughput capacity. The remainder substations with low roofing and high shelter can construct the $230 \mathrm{MHz}$ base stations to make auxiliary coverage. The substations adjacent to several $1.8 \mathrm{GHz}$ base stations can also consider to construct a $230 \mathrm{MHz}$ base station to reduce Co-Channel interference in $1.8 \mathrm{GHz}$ frequency as well as insure the signal coverage of the power private wireless network.



Figure 6. Mode1: $1.8 \mathrm{GHz}$ base stations as the main signal coverage and $230 \mathrm{MHz}$ base stations as auxiliary signal coverage in urban area.

Mode2 is showed in Figure 7. Distribution rooms have a sparse deployment in the suburb area, so the substations with high roofing and low shelter can construct the $230 \mathrm{MHz}$ base stations to ensure signal coverage. The remainder substations adjacent to several $1.8 \mathrm{GHz}$ base stations can also considered to construct a $1.8 \mathrm{GHz}$ base station as auxiliary coverage to reduce Co-Channel interference in $230 \mathrm{MHz}$ frequency, and the DTU(Distribution Terminal Unit) in the signal overlap area of several $230 \mathrm{MHz}$ base stations can access the master station ${ }^{[3]}$ by $1.8 \mathrm{GHz} \mathrm{CPE}$ (Customer Premises Equipment) to avoid frequent detaches caused by $\mathrm{Co}-$ Channel interference. 


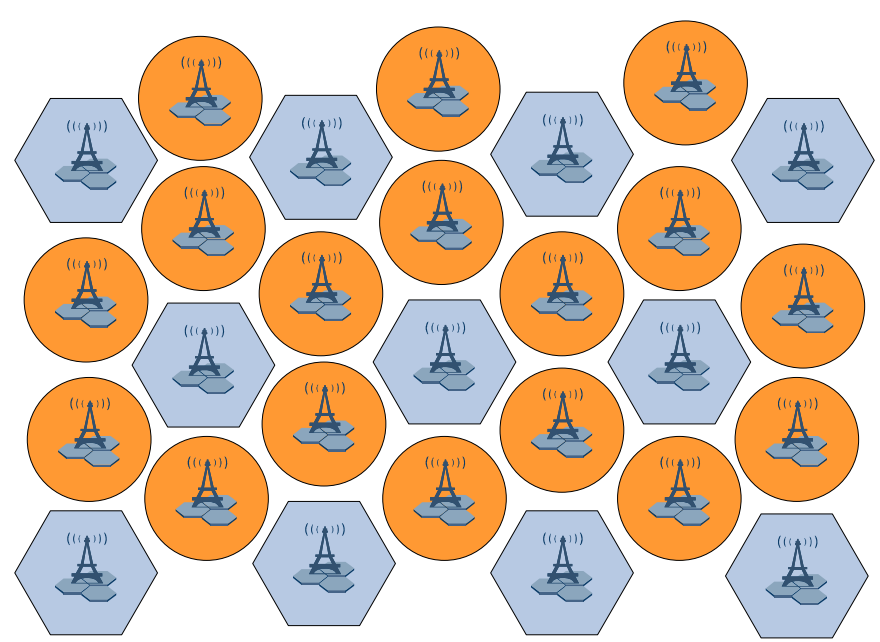

Figure 7. Mode2: $230 \mathrm{MHz}$ base stations as the main signal coverage and $1.8 \mathrm{GHz}$ base stations as auxiliary signal coverage in suburb area.

\section{Conclusions}

The interlacing networking model for TD-LTE power private wireless network in multiple frequency bands presented in this paper can avoid the unstable communication causing by frequent cell handover as well as reduce the signal blind zones. Moreover, develop communication terminals which can work in both $230 \mathrm{MHz}$ and $1.8 \mathrm{GHz}$ power private network can improve the handover performance of this interlacing networking model.

\section{References}

1. WANG Hao,ZHONG Yu-qing,RONG Zhineng,CHEN Bao-ren.Research of Multi-frequency Hybrid Networking of TD-LTE Power Wireless Broadband System, Electric Power Information and Communication Technology. 2013, 11(8):24-30.

2. LI Wen-wei, CHEN Bao-ren, WU Qian, LAI Mu-bo. Applied Research of TD-LTE Power Wireless Broadband Private Network. Telecommunications for Electric Power System.2012, 33(11):82-87.

3. ZHANG Lan. Overview of power distribution automation communication technologies. Telecommunications for Electric Power System. 2008, 29(4): 42-46. 